\title{
PROSSIGA:Auxiliando o Aprendizado de Programação com o Uso da Robótica
}

\author{
Arthur B. Duarte ${ }^{1}$, Artur A. S. Servian ${ }^{2}$, Paulo R. B. Branquinho ${ }^{2}$, \\ Ygor S. Neves ${ }^{3}$, Carlos R. Lopes ${ }^{1}$ \\ ${ }^{1}$ Faculdade de Computação - Universidade Federal de Uberlândia (UFU) \\ ${ }^{2}$ Faculdade de Engenharia Mecânica - Universidade Federal de Uberlândia \\ ${ }^{3}$ Faculdade de Engenharia Elétrica - Universidade Federal de Uberlândia \\ \{abrothguer, arturazeredo, pauloricardobueno01\}@gmail.com \\ ygor15hbegmail.com, crlopes@ufu.br
}

\begin{abstract}
In introductory courses of programming the students feel great difficulty in understanding the concepts and the logic of the programming, which leads to failures and even in course evasion. In this paper we describe an approach based on the use of robotics to mitigate the above difficulties. Although there are several proposals that make use of robotics to assist the student in learning programming few show detail and accuracy with respect to the results obtained. As a result of this we have developed our proposal with focus on teaching programming for higher education. The obtained results were good, but certain fragilities detected must be overcome so that better results can be achieved in the future.
\end{abstract}

Resumo. Em disciplinas introdutórias de programação os alunos sentem uma grande dificuldade em entender os conceitos e a lógica da programação, o que leva à reprovações ou trancamentos na disciplina e até mesmo na desistência do curso. Neste artigo descrevemos uma abordagem baseada no uso de robótica para mitigar as dificuldades anteriormente mencionadas. Apesar de existirem diversas propostas que fazem uso de robótica para auxiliar o aluno no aprendizado de programação poucas mostram detalhamento e rigor com relação aos resultados obtidos. Em função disto desenvolvemos nossa proposta voltada ao ensino de programação para a educação superior. Os resultados obtidos foram bons, mas certas fragilidades detectadas devem ser superadas para que melhores resultados possam ser obtidos futuramente.

\section{Introdução}

Uma disciplina que ensina os conceitos básicos de programação faz parte da grade curricular de diversos cursos das áreas de exatas, humanas e biológicas. Embora caracterizadas por uma mesma ementa acabam recebendo diversas denominações tais como Introdução à Programação, Introdução à Ciência da Computação, Introdução à Programação de Computadores, Lógica de Programação, entre outras. O foco principal dessas disciplinas é 
VIII Congresso Brasileiro de Informática na Educação (CBIE 2019)

Anais do XXV Workshop de Informática na Escola (WIE 2019)

que o aluno aprenda a fazer algoritmos [Forbellone e Eberspächer 2005]. Tais disciplinas adotam linguagens de programação como C, C++, Java, Python, entre outras na implementação dos algoritmos. Para [Santos e Costa 2006], os alunos sentem uma grande dificuldade em entender os conceitos de introdução à programação, levando à reprovações ou trancamentos na disciplina e até desistência do curso. Portanto, faz-se necessário o desenvolvimento/emprego de técnicas que possam minimizar a dificuldade do aprendizado, o que levará a uma diminuição dos níveis de reprovação/evasão.

A fim de corroborar com a informação descrita no parágrafo anterior os autores fizeram um levantamento de disciplinas que envolvem o ensino de conceitos básicos de programação na Universidade Federal de Uberlândia. Para tais disciplinas identificou-se a situação de aprovados, reprovados e de abandonos ocorridos ao longo de um período de 3 anos (2016 a 2018). A Figura 1 descreve o desempenho geral dos alunos.

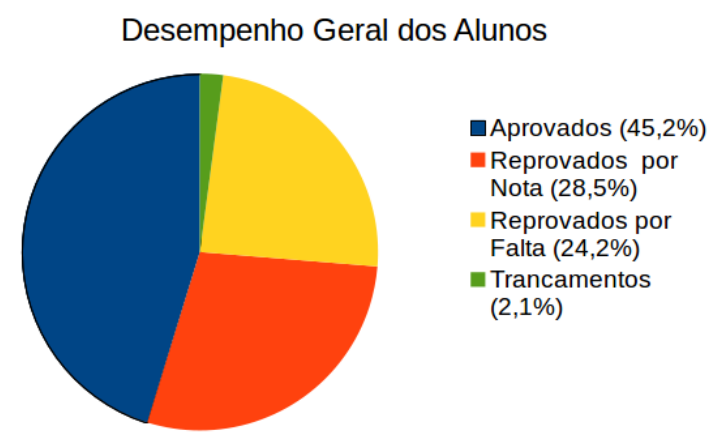

\section{Figura 1. Desempenho dos alunos de Introdução a Programação no período 2016-2018}

Observa-se que no período mencionado 45,2\% dos alunos foram aprovados, $28,5 \%$ foram reprovados por nota, 24,2\% foram reprovados por freqüência e 2,1\% não finalizaram em função de trancamento. Portanto, tem-se um elevado índice de reprovação e abandono (considerando-se as reprovações por faltas e trancamentos).

Uma das abordagens defendidas para combater os níveis de reprovação/trancamento em disciplinas introdutórias de programação é fazer uso da robótica. Neste sentido diversas propostas tem empregado robôs e muitas delas fazem uso do kit Lego Mindstorms [Lego 2019].

Neste artigo descrevemos o emprego do Lego Mindstorms como atividade complementar de uma disciplina introdutória de programação com o objetivo de medir sua efetividade como elemento motivador permitindo assim que haja uma minimização das dificuldades de aprendizado dos conteúdos relacionados a uma disciplina introdutória de programação. O trabalho foi desenvolvido pelo NUPEME/FACOM, que é um núcleo de pesquisadores em mídias e Informática na Educação. Em termos de pesquisa científica o objetivo é investigar o impacto do uso de robótica em cursos introdutórios de computação. A motivação para o trabalho neste projeto, doravante PROSSIGA, veio da constatação dos elevados índices de reprovação e evasão em disciplinas introdutórias de programação em cursos superiores e do uso da robótica como possível recurso para combater tais dificuldades. Apesar de existirem diversos trabalhos que abordem o tema [Mattos et al. 2015, Neto et al. 2015] observou-se que poucos abordam de uma forma rigorosa sua proposta implementada e que existe pouco detalhamento da metodologia em- 
VIII Congresso Brasileiro de Informática na Educação (CBIE 2019)

Anais do XXV Workshop de Informática na Escola (WIE 2019)

pregada. Assim buscou-se neste trabalho um rigor quanto à metodologia e coleta dos resultados, uma das grandes contribuições deste trabalho. Como resultado do trabalho desenvolvido, várias atividades didáticas foram implementadas e serão disponibilizadas para a comunidade.

As demais seções deste artigo encontram-se estruturadas conforme a descrição que segue. A seção 2 detalha o desenvolvimento do trabalho. A seção 3 descreve e discute os resultados obtidos. Uma conclusão é apresentada na seção 4.

\section{Materiais e Métodos}

A disciplina introdutória de programação alvo do projeto foi a disciplina Algoritmos e Programação de Computadores do curso de Engenharia Mecânica. Em tal disciplina a linguagem de programação usada é a linguagem C. Em função disto utilizouse o kit lego MindStorms NXT e a linguagem NXC, uma linguagem para programação baseada em C. Foram utilizados também 6 kits Lego Mindstorms EV3 e o ambiente C4EV3 [Perez et al. 2015] para programação dos robôs usando a linguagem C.

O desenvolvimento do projeto foi realizado em cinco etapas que se encontram especificadas a seguir. Observa-se que a realização das etapas a seguir não necessariamente seguiu a ordem em que estão descritas, pois algumas puderam ser realizadas de forma intercalada.

Na primeira etapa procedeu-se com a seleção e capacitação dos membros da equipe.Na etapa seguinte foi feita uma revisão bibliográfica da literatura identificando abordagens para a inserção da robótica em cursos introdutórios de programação com a participação de todos os membros da equipe. Isto permitiu que numa próxima etapa se pudesse criar todo o necessário para o estabelecimento da proposta de oferecimento de atividades de robótica para o público alvo: elaboração das atividades a serem oferecidas, questionários para avaliações e carga horária necessária para a realização das atividades.A etapa seguinte consistiu no oferecimento das atividades para o público alvo do projeto. Ressalta-se que as atividades didáticas realizadas pelos alunos estiveram em consonância com a seqüência de contéudos comumente apresentada na disciplina de tal forma que o aluno pudesse aplicar o conhecimento adquirido na programação dos robôs.Encerradas as atividades e coletado o material resultante de questionários e de entrevistas com os alunos elaborou-se um relatório detalhando-se os resultados obtidos.

\section{Resultados}

As atividades e desafios propostos em sala de aula foram bem sucedidos apesar das dificuldades encontradas pelos alunos. Entretanto algumas atividades não puderam ser finalizadas dentro do prazo proposto. Alegou-se que as provas e trabalhos finais de outras disciplinas do curso estariam exigindo muito dedicação.

No segundo semestre de 2018 sessenta alunos se matricularam na disciplina Algoritmos e Programação de Computadores (APC). Um total de 22 alunos se inscreveu para participar do projeto PROSSIGA. Novamente reforça-se que por questões metodológicas foi facultada aos alunos a participação no projeto.

Com relação ao impacto do projeto referente ao sucesso dos alunos na disciplina observa-se que a maior parte dos alunos foi aprovada como se pode observar na Figura 2. 
VIII Congresso Brasileiro de Informática na Educação (CBIE 2019)

Anais do XXV Workshop de Informática na Escola (WIE 2019)

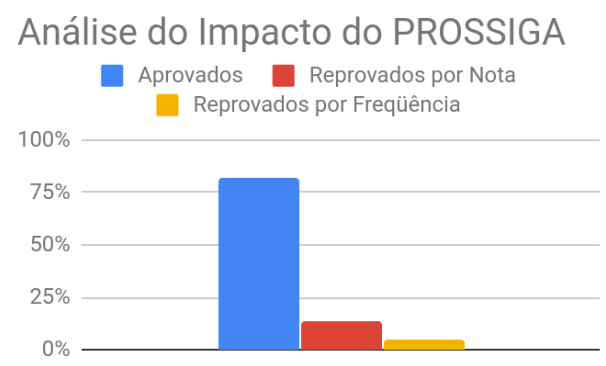

\section{Figura 2. Níveis de Aprovação/Reprovação na Disciplina dos Alunos Participan- tes do PROSSIGA}

Uma outra observação refere-se ao fato de que as notas finais dos alunos que participaram do PROSSIGA foi bem maior daqueles que não como pode se observar na Figura 3. Mesmo aqueles que foram reprovados obtiveram uma nota final superior aos que foram reprovados e não participaram do projeto.

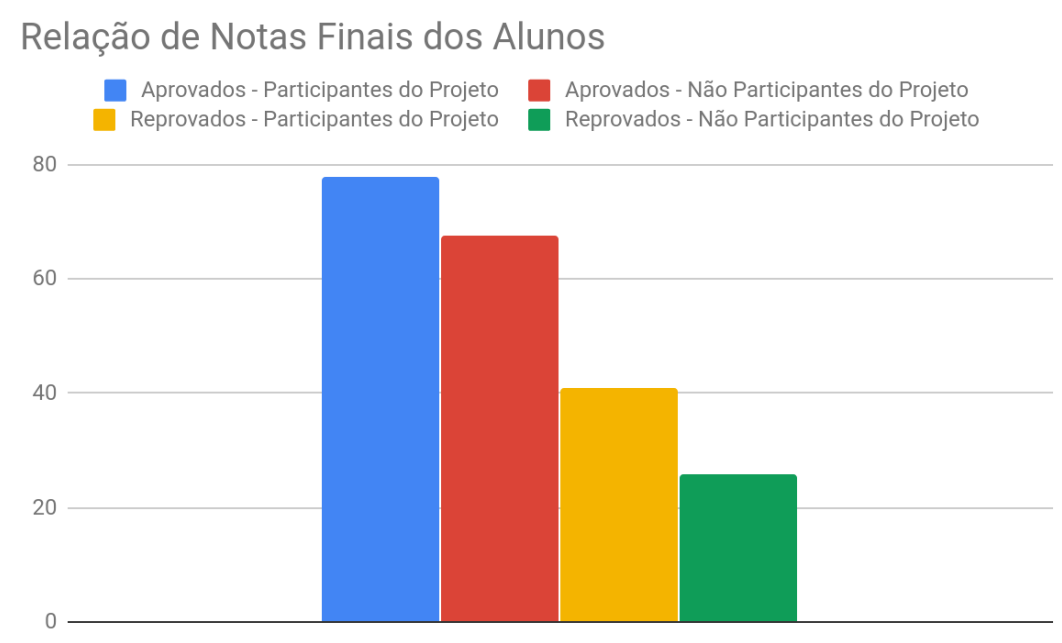

Figura 3. Notas Finais dos Alunos na Disciplina de Algoritmos e Programação de Computadores

Os alunos que participaram do projeto expressaram sua opiniões, algumas das quais aparecem especificadas a seguir.

"Um projeto onde se pode ver a aplicação real da matéria de programação, de modo a facilitar o aprendizado do aluno".

"main() printf("Muito bom");".

Os professores responsáveis pela disciplina também expressaram sua opinião conforme o texto que segue.

"A maioria dos alunos da lista que você me enviou, (alunos do projeto), foram extremamente participativos durante as aulas e tiveram um bom desempenho na disciplina. Eu ministrei praticamente a mesma matéria na Estatística e na Engenharia Ambiental, entretanto, os alunos da Engenharia Mecânica se destacaram muito. Eles entendiam a matéria com mais facilidade e mostravam mais interesse."- (professora da disciplina) 
VIII Congresso Brasileiro de Informática na Educação (CBIE 2019)

Anais do XXV Workshop de Informática na Escola (WIE 2019)

Um questionário foi passado para os alunos que continuaram no PROSSIGA até o seu término e outro para aqueles que desistiram. Dos alunos desistentes $98 \%$ alegaram falta de tempo, $1 \%$ por desistência da disciplina e $1 \%$ por outros motivos.

\section{Conclusão}

É indiscutível que robótica é um tema que desperta a curiosidade e o interesse do aluno em querer conhecer mais a respeito. Apesar da participação do aluno ser facultativa uma boa parte dos alunos que cursava a disciplina introdutória de programação inscreveu-se para participar do PROSSIGA. De acordo com os dados apresentados anteriormente a maioria dos alunos que participaram do projeto tiveram êxito na disciplina e gostaram muito do que aprenderam. Apesar disto na realização do trabalho identificamos algumas fragilidades que necessitam ser alvos de uma investigação futura:

- desistência de alguns alunos justificando a necessidade de atenção em outras disciplinas do curso;

- número limitado de kits de robótica. A disponibilidade de um número maior poderia fazer com que uma disponibilidade de tempo maior fosse dada ao projeto;

Desta forma mais experimentos deverão ser realizados em futuro próximo objetivando melhorar os resultados obtidos.

Também observa-se que não existe uma ontologia para a robótica educacional com foco em ensino de programação. Trata-se de um desenvolvimento futuro interessante que poderá fazer com que os trabalhos desenvolvidos na área possam rapidamente se beneficiar dos resultados obtidos e se integrar com outras ontologias existentes relacionadas a robótica.

\section{Referências}

Forbellone, A. e Eberspächer, H. (2005). Lógica de Programação : a construção de algoritmos e estruturas de dados. Pearson Prentice Hall.

Lego (2019). Lego mindstorms. Disponível em http://mindstorms.lego.com/enus/Default.aspx.Último acesso em 10/06/2019.

Mattos, S. D. G., de Oliveira, V. M., Soares, L. B., de Aguiar, Y. Q., e Maciel, B. K. (2015). Introdução à robótica e estímulo à lógica de programação no ensino básico utilizando o kit educativo lego $(\mathbb{R}$ mindstorms. Anais dos Workshops do Congresso Brasileiro de Informática na Educação.

Neto, R. P. B., Santana, A. M., Rocha, D. P., e Souza, A. (2015). Robótica na educação: Uma revisão sistemática dos Últimos 10 anos. Simpósio Brasileiro de Informática na Educação - SBIE.

Perez, S. R., Gold-Veerkamp, C., Abke, J., e Borgeest, K. (2015). A new didactic method for programming in c for freshmen students using lego mindstorms ev3. Proceedings of 2015 International Conference on Interactive Collaborative Learning (ICL).

Santos, R. e Costa, H. (2006). Análise de metodologias e ambientes de ensino para algoritmos, estruturas de dados e programação aos iniciantes em computação e informática. INFOCOMP. 